\section{In Reply: The Preservation of Cognition 1 Year After Carotid Endarterectomy in Patients With Prior Cognitive Decline}

To the Editor:

We have read with enthusiasm the referenced letter ${ }^{1}$ in regards to our publication in Neurosurgery "The Preservation of Cognition 1 Year after Carotid Endarterectomy in Patients with Prior Cognitive Decline". ${ }^{2}$

We would like to take this opportunity and thank the authors ${ }^{1}$ for their kind words regarding our paper $^{1}$; we agree with the writers that these are clinical important questions such as the ones they are asking, that need to be addressed prospectively.

We agree that longitudinal brain change after CEA is of interest. Furthermore, we are planning magnetic resonance studies of the course of white matter and microvascular changes of the brain of patients at risk for stroke. The answers to some of the letter writer(s) questions will need to await such further studies.

Thank you for your kind words in considering our study a fundamental reference in your current research.

\section{Disclosures}

This work was supported by the National Institutes of Health (grant number RO1 NS064034 PI: R. Dempsey), the Rath Distinguished Graduate Foundation Research Award (funded author Sara Berman), The Medical Scientist Training Program AH (funded author Sara Berman), Neuroscience Training Program MH, T32GM007507 (funded author Sara Berman), the Wisconsin's Alzheimer Disease Research Center P50-AG03351 (funded authors Sterling Johnson and Sara Berman). Dr Mitchell may have future royalties from Davies Publishing (authorship for 2 Echocardiography textbooks, currently under review), and may have future royalties from textbook chapters published by Elsevier and Wolters Kluwer. Dr Varghese has a research agreement for use of ultrasound research interface with Siemens Ultrasound with no financial benefits. The authors have no personal, financial, or institutional interest in any of the drugs, materials, or devices described in this article.
Nirvedh H. Meshram, BE ${ }^{\| \#}$

Tomy Varghese, $\mathrm{PhD} \|$

Bruce P. Hermann, PhD**

*Department of Neurological Surgery

University of Wisconsin School of Medicine and Public Health

Madison, Wisconsin

${ }^{*}$ Wisconsin Surgical Outcomes Center Research Program

Department of Surgery

University of Wisconsin School of Medicine and Public Health

Madison, Wisconsin

${ }^{\lessgtr}$ Department of Medicine Cardiovascular Medicine Division

University of Wisconsin School of Medicine and Public Health

Madison, Wisconsin

'Alzheimer's Disease Research Center

University of Wisconsin School of Medicine and Public Health

Madison, Wisconsin

"Department of Medical Physics

University of Wisconsin School of Medicine and Public Health

Madison, Wisconsin

\#Department of Electrical and Computer Engineering

University of Wisconsin-Madison

Madison, Wisconsin

** Department of Neurology University

Wisconsin School of Medicine and Public Health

Madison, Wisconsin

\section{REFERENCES}

1. Nagm A, Horiuchi T, Hongo K. Letter: The Preservation of Cognition 1 Year after Carotid Endarterectomy in Patients With Prior Cognitive Decline. Neurosurgery. 2018;83(4):E179-E180.

2. Dempsey RJ, Jackson DC, Wilbrand SM, et al. The Preservation of Cognition 1 Year After Carotid Endarterectomy in Patients With Prior Cognitive Decline. Neurosurgery. 2018;82(3):322-328.

\section{Acknowledgments}

Robert J. Dempsey, MD*

Daren C. Jackson, $\mathrm{PhD}^{\ddagger}$

Stephanie M. Wilbrand, PhD* $^{*}$

Carol C. Mitchell, $\mathrm{PhD}^{\S}$

Sara E. Berman, MS

Sterling C. Johnson, $\mathrm{PhD}^{9}$
The authors would like to extend their deepest gratitude to all individuals who participated in this study. 